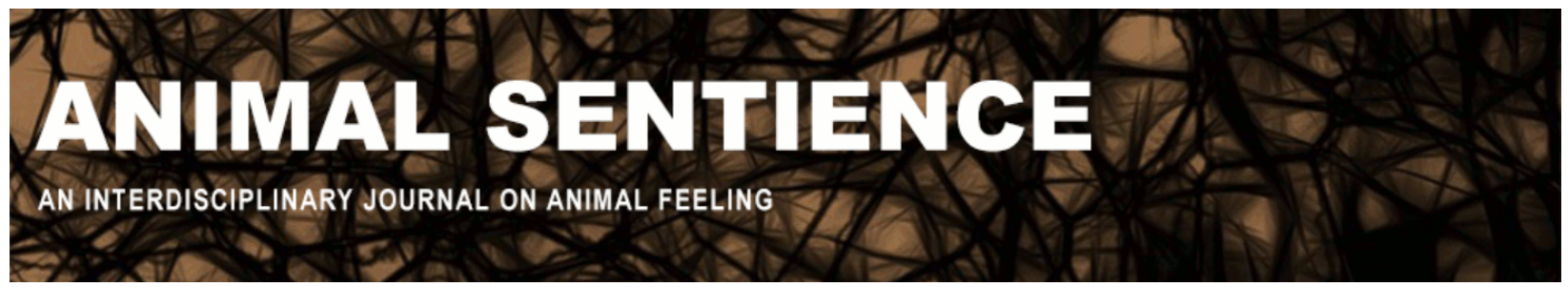

Leadbeater, Simon R. B. (2016) Animal suffering calls for more than a bigger cage. Animal Sentience 7(4)

DOI: $10.51291 / 2377-7478.1081$

Date of submission: 2016-01-17

Date of acceptance: 2016-01-25

(c)

This article has appeared in the journal Animal

Sentience, a peer-reviewed journal on animal

cognition and feeling. It has been made open access,

free for all, by WellBeing International and deposited

in the WBI Studies Repository. For more information,

please contact

wbisr-info@wellbeingintl.org.

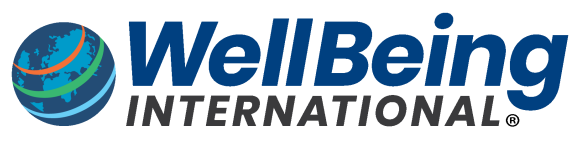

SOLUTIONS FOR PEOPLE, ANIMALS AND ENVIRONMENT 


\title{
Animal suffering calls for more than a bigger cage
}

Commentary on $\mathrm{Ng}$ on Animal Suffering

\author{
Simon Leadbeater \\ Independent Environmental Consultant
}

\begin{abstract}
Ng (2016) argues for incremental welfare biology partly because it would be impossible to demonstrate conclusively that animals are sentient. He argues that low-cost changes in industrial practices and working collaboratively may be more effective in advancing animal welfare than more adversarial approaches. There is merit in some of $\mathrm{Ng}^{\prime} \mathrm{s}$ recommendations but a number of his arguments are, in my view, misdirected. The fact that nonhuman animals feel has already been adequately demonstrated. Cruelty to animals is intrinsic to some industries, so the only way to oppose it is to oppose the industry.
\end{abstract}

\begin{abstract}
Simon Leadbeater simon.leadbeater@btinternet.com is an independent consultant and researcher. He has written for the Ecologist; the Voluntary Sector Review; Hertfordshire Life; The Quarterly Journal of Forestry; and ECOS, the Journal of the British Association of Nature Conservationists. His book, The Politics of Textiles, based on his doctoral research, was published by Sage Publications. His main challenge lies in restoring an ancient woodland. http://priorsenvironmental.com
\end{abstract}

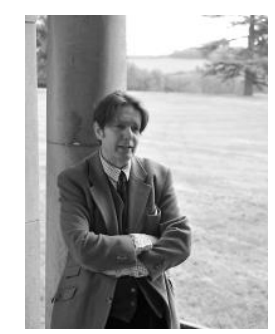

Professor Ng's (2016) target article has two separate - almost stand-alone - components. The first is his section on "Welfare Biology vs. the World Knot," which centres on whether animals are conscious and capable of suffering. $\mathrm{Ng}$ concludes that animals are indeed capable of suffering, which leads him in the second half of his article to suggest ways in which their suffering can be minimised. Here he argues that animal suffering can be reduced through low-cost, common sense approaches, working collaboratively with industry, and with animal advocates gradually gaining more influence.

In my judgement the first section of $\mathrm{Ng}^{\prime}$ s article still expresses uncertainty about a premise that animals feel - that has by now been recognised as true by almost everyone. A weakness in $\mathrm{Ng}^{\prime} \mathrm{s}$ second section is that $\mathrm{Ng}$ does not seem to realise how inseparable nonhuman animal suffering is from the nature and product of certain industries. There are other elements of $\mathrm{Ng}^{\prime}$ ' argument that I struggle with; but none of this is to deny that adopting a co-operative stance has sometimes achieved some results and will continue to do so in the future.

\section{Ng's Welfare Biology vs. the World Knot}

Discussions centring on the World Knot (consciousness) are not for the faint-hearted; this is the least accessible component of $\mathrm{Ng}^{\prime}$ 's target article. Although $\mathrm{Ng}$ seems to dismiss the idea that the concept of consciousness will be understood any time soon, he does suggest that if a species is capable of acting flexibly, then it is capable of feeling, hence of suffering and 
enjoyment. He states that the only certainty of feeling is what we as individuals experience, and that we cannot extend this certainty even to our spouses. (I like this observation.)

But to my mind the argument about whether nonhuman animals feel is already won, as summarised, for example, among scientists, in the Cambridge Declaration on Consciousness (Low et al. 2012). As expressed for laymen in the words of the Andrew Linzey (2011) of the Oxford Centre for Animal Ethics: "scientific data demonstrate that all mammals, at least, experience not just physical pain, but also mental suffering, including fear, foreboding, shock, trauma, stress, distress, anticipation, and terror - all states previously regarded as exclusive to human beings." Versions of this position have been held by scientists and philosophers, from Darwin to Bentham. It is puzzling that we still need to justify this today. According to Rollin (2007), questioning whether nonhuman animals possess minds and consciousness only came about because of a change in values and not through any scientific justification. In addition, although I am not sure whether $\mathrm{Ng}$ had this in mind, the insight he offers in referring to the inscrutability of his spouse is that if within our own species it cannot be known with certainty whether and what someone else is feeling, then we could argue that the situation with animals is quite comparable: Yet we do not allow industry to cause our spouses to suffer, nor merely to diminish their suffering incrementally as long as it involves no additional cost to industry.

\section{Ways of reducing animal suffering}

The principle that policy makers should ban mild to deplorable cruelty is unassailable. But $\mathrm{Ng}$ 's point about increasing the minimum cage size for factory-farmed chickens suggests that he does not fathom the depth of the problem. For several years now I have kept ex-battery chickens; I have not noticed any difference in the condition of "rescued" hens since battery cages were replaced by so called "enriched" cages in 2012. Owing to the stress of their earlier lives, mortality is very high - few rescued chickens live for even a year after release, whereas a chicken's natural lifespan is 15 years or more. And well before that, all male chicks are either gassed or "macerated" irrespective of whether they are free-range or not. It is nearly futile to rescue broiler chickens because soon after release they invariably die from heart failure. (This is no problem for the industry, as these unfortunate creatures are routinely slaughtered when they are between 5 and 7 weeks of age.) In other words, as Berkman (2012: 135) argues, "cruelty is not a mere evil side effect or by-product ... cruelty is ... an essential and necessary part of the logic of factory farming." To eradicate suffering in the poultry industry requires the elimination of the industry itself.

In addition to seeming unaware that all animal farming inescapably entails animal suffering, $\mathrm{Ng}$ suggests that to improve animal welfare we should focus first on farm animals and not on wild animals and their suffering and destruction from habitat encroachment. When $\mathrm{Ng}$ writes "it may be wise to leave most measures on [wild animals'] behalf to the future," the obvious retort is that, unless we act, wild animals won't have a future (Ceballos et al., 2015).

$\mathrm{Ng}$ also argues that animal advocates would achieve more if they resisted exaggerating. He says Bekoff's (2013) book is hyperbolic because of the claim that the size of an animal's brain is not related to its capacity to feel. Surely the important point is that while we may feel intuitively that size matters, when it comes to feelings, empirical evidence increasingly suggests that this is incorrect. When we learn that ants can die of loneliness (Koto, 2015) and 
that woodlice have different personalities (Tuf, 2015), it should make us think about such invertebrates rather differently.

$\mathrm{Ng}$ closes noting that the easy, low-cost options are just the starting point for eliminating suffering. Perhaps, but $\mathrm{Ng}$ fails to realise that animal suffering is an inherent component of some industries; hence campaigning against those industries themselves would seem the only possible route to eliminating cruelty. ${ }^{1}$

In some circumstances the principle of working with rather than against industry may be an efficacious strategy. I am not convinced, however, that incremental welfare biology can contribute as much to relieve animal suffering as the call by Bekoff and Pierce (2009), Safina (2016), and others for a fundamental change in our relationship with animals in view of the fact that they feel - rather than just (as Ng perhaps inadvertently implies) giving them a bigger cage.

\section{Acknowledgements}

I would like to thank Professor Stevan Harnad for his editorial help in preparing this commentary.

\section{References}

Baluška, F. (2016) Should fish feel pain? A plant perspective. Animal Sentience 2016.023

Bekoff, M. (2013) Why dogs hump and bees get depressed. New World Library

Bekoff, M., \& Pierce, J. (2009) Wild justice: The moral lives of animals. University of Chicago Press

Berkman, J. (2012) Are we addicted to the suffering of animals? Animal cruelty and the Catholic moral tradition In Alex-Baker, A. (Ed.), A faith embracing all creatures: Addressing commonly asked questions about Christian care for animals. Tripp York

Ceballos, G., Ehrlich, A. H., \& Ehrlich, P. R. (2015) The annihilation of nature: Human extinction of birds and mammals. Johns Hopkins University Press

Koto, A., Mersch, D., Hollis, B., \& Keller, L. (2015) Social isolation causes mortality by disrupting energy homeostasis in ants. Behavioral Ecology and Sociobiology, 69(4), 583591

Linzey, A., The Revd. Prof., Sermon at Westminster Abbey on $2^{\text {nd }}$ October 2011: http://www.oxfordanimalethics.com/what-we-do/commentary/address-at-westminsterabbey/

\footnotetext{
1 This should perhaps not be assumed for all forms of farming: Although it is clear that, in practice, the approach could not scale up to global consumption levels, at Ahimsa Milk no cows are ever slaughtered, including male calves, so, in principle, producing modest quantities of milk need not be cruel.
} 
Low, P., Panksepp, J., Reiss, D., Edelman, D., \& Van Swinderen, B. (2012) The Cambridge declaration on consciousness. Francis Crick Memorial Conference on Consciousness in Human and Non-Human Animals, Churchill College, University of Cambridge, July 7, 2012

Ng, Y-K. (2016) How welfare biology and commonsense may help to reduce animal suffering. Animal Sentience 2016.007

Rollin, B. E. (2007) Animal mind: Science, philosophy, and ethics. The Journal of Ethics, 11: 253-274

Safina, C. (2016) Animals think and feel: Précis of Beyond words: What animals think and feel (Safina 2015) Animal Sentience 2016.002

Tuf, I. H., Drábková, L., \& Šipoš, J. (2015) Personality affects defensive behaviour of Porcellio scaber (Isopoda, Oniscidea). ZooKeys 515: 159-171. DOI: 10.3897/zookeys.515.9429 